\title{
Neuronal pentraxin 1: a synaptic-derived plasma biomarker in Alzheimer's disease
}

Qiu-Lan Ma1,2, Edmond Teng ${ }^{1,2}$, Xiaohong Zuo ${ }^{1,2}$, Mychica Jones ${ }^{1,2}$, Bruce Teter $^{1,2}$, Evan Y. Zhao ${ }^{1,2}$, Cansheng Zhu ${ }^{1,3}$, Tina Bilousova ${ }^{4}$, Karen H. Gylys ${ }^{4}$, Liana G. Apostolova ${ }^{5}$, Mary Jo LaDu6 ${ }^{6}$, Mir Ahamed Hossain 7 , Sally A. Frautschy ${ }^{1,2}$, Gregory M. Cole ${ }^{1,2}$

${ }^{1}$ Department of Neurology, David Geffen School of Medicine, University of California, Los Angeles; 2 Veterans Affairs Greater Los Angeles Healthcare System; ${ }^{3}$ Department of Neurology, The Third Affiliated Hospital, Sun Yat-sen University, Guangzhou, China; ${ }^{4}$ School of Nursing, University of California, Los Angeles; ${ }^{5}$ Departments of Neurology, Radiology, and Medical and Molecular Genetics, Indiana University School of Medicine; ${ }^{6}$ Department of Anatomy and Cell Biology, University of Illinois at Chicago; ${ }^{7}$ The Johns Hopkins University School of Medicine, the Kennedy Krieger Institute.

Correspondng authors: Qiu-Lan Ma, QiulanMa@mednet.ucla.edu; Greg. M Cole, GregoryCole@mednet.ucla.edu. Address: Mary S. Easton Translational Center, Veterans Greater Los Angeles Healthcare, 11301 Wilshire Blvd. Bldg 114, room 114-3. Los Angeles, CA 90073. Tel: 310-478-3711, ext. 42171, Fax: 310-260-4083

Conflicts of interest: none

This is the author's manuscript of the article published in final edited form as:

Ma, Q.-L., Teng, E., Zuo, X., Jones, M., Teter, B., Zhao, E. Y., ... Cole, G. M. (2018). Neuronal pentraxin 1: A synaptic-derived plasma biomarker in Alzheimer's disease. Neurobiology of Disease, 114, 120-128. https://doi.org/10.1016/j.nbd.2018.02.014 


\section{Abstract:}

Synaptic neurodegeneration is thought to be an early event initiated by soluble $\beta$-amyloid $(A \beta)$ aggregates that closely correlates with cognitive decline in Alzheimer disease (AD). Apolipoprotein $\varepsilon 4$ (APOE4) is the most common genetic risk factor for both familial $A D(F A D)$ and sporadic $A D$; it accelerates $A \beta$ aggregation and selectively impairs glutamate receptor function and synaptic plasticity. However, its molecular mechanisms remain elusive and these synaptic deficits are difficult to monitor. AD- and APOE4-dependent plasma biomarkers have been proposed, but synapse-related plasma biomarkers are lacking. We evaluated neuronal pentraxin 1 (NP1), a potential CNS-derived plasma biomarker of excitatory synaptic pathology. NP1 is preferentially expressed in brain and involved in glutamate receptor internalization. NP1 is secreted presynaptically induced by $A \beta$ oligomers, and implicated in excitatory synaptic and mitochondrial deficits. Levels of NP1 and its fragments were increased in a correlated fashion in both brain and plasma of 7-8 month-old E4FAD mice relative to E3FAD mice. NP1 was also found in exosome preparations and reduced by dietary DHA supplementation. Plasma NP1 was higher in E4FAD+ $\left(A P O E 4^{+/+} / \mathrm{FAD}^{+/-}\right)$relative to E4FAD- (non-carrier; $A P O E 4^{+/+} / \mathrm{FAD}^{-/-}$) mice, suggesting NP1 is modulated by $A \beta$ expression. Finally, relative to normal elderly, plasma NP1 was also elevated in patients with mild cognitive impairment (MCl) and elevated further in the subset who progressed to early-stage $A D$ dementia. In those patients, there was a trend towards increased NP1 levels in APOE4 carriers relative to non-carriers. These findings indicate that NP1 may 
represent a potential synapse-derived plasma biomarker relevant to early alterations in excitatory synapses in $\mathrm{MCl}$ and early-stage $\mathrm{AD}$.

Keywords: Alzheimer disease, $\beta$-amyloid, plasma biomarkers, neuronal pentraxin 1, APOE, MCl, dementia, EFAD mice

\section{Highlights}

- Neuronal pentraxin 1 (NP1) is a potential plasma biomarker of synaptic dysfunction.

- NP1 is increased in both brain and plasma in mouse models of AD.

- In transgenic AD mice, brain and plasma NP1 levels correlated closely.

- Both brain and plasma NP1 levels were reduced by DHA supplementation.

- NP1 is increased in patients with $\mathrm{MCl}$ and mild AD dementia.

\section{Introduction}

Synaptic degeneration is one of the earliest pathological hallmarks of Alzheimer disease (AD). Synapse loss, not $A \beta$ burden, is the major correlate of cognitive impairment and disease progression (Terry et al., 1991). Thus therapeutic strategies for $A D$ should include synapse-protective interventions (Shankar et al., 2007) but synaptic degeneration cannot be directly monitored. Overwhelming evidence supports the idea that soluble oligomeric $A \beta$ (OA $\beta$ ) represents the major $A \beta$ toxic species that contributes to early synaptic and cognitive deficits in AD (Ma et al., 2006, Shankar et al., 2007, Gong and lqbal, 2008, Tomic et al., 2009, Danysz and Parsons, 2012, Ma et al., 2013), involving 
both NMDA receptor dysregulation (Guntupalli et al., 2016) and NMDA receptor-induced excitotoxicity (Snyder et al., 2005, Shankar et al., 2007, Li et al., 2011).

The APOE4 allele is the most common genetic risk factor for AD. It increases $A D$ risk by $4-15$ fold and is present in more than half of all patients with $\mathrm{MCl}$ or dementia due to $\mathrm{AD}(\mathrm{Bu}, 2009$, Hua et al., 2011). Human APOE4 accelerates amyloid deposition, reduces amyloid clearance and glucose uptake, and stabilizes $O A \beta$. Since clinical symptoms of $A D$ only emerge after apparently irreversible neurological degeneration, early interventions in high-risk APOE4 carriers may require early diagnostic and surrogate biomarkers. ApoE4 increases the oligomerization of $A \beta$ (Hashimoto et al., 2012) and the concentrations of $\mathrm{oA} \beta$ within the interstitial fluid (Hudry et al., 2013), co-localizes with $\mathrm{OA} \beta$, and enhances synaptic oA $\beta$ localization (Koffie et al., 2012). However, we lack $A \beta$ and/or apoE4-regulated synapse-derived blood biomarkers for clinical studies.

ApoE4 also appears to modulate cerebral metabolism independently of its effects on $A \beta$ deposition (Jagust et al., 2012), as regional reductions in fluorodeoxyglucose-positron emission tomography (FDG-PET) signaling can be seen in younger APOE4 carriers several decades prior to $A \beta$ deposition and the possible onset of dementia (Reiman et al., 2004). This may be a direct consequence of apoE4-mediated synaptic deficits, which include downregulation of synaptic mitochondrial proteins (Shi et al., 2014) and dendritic spines (Dumanis et al., 2009). The selective effects of apoE4 (versus apoE3) on mitochondria and excitatory synapses could be related to APOER2/reelin 
receptor control of AMPA and NMDA receptor surface activity (Chen et al 2010).

Neuronal pentraxin 1 (NP1) and its receptor (NPR) are primarily expressed in excitatory neurons, where NPR is involved in the function of AMPA receptors at the synapse (Schlimgen et al., 1995, Cho et al., 2008) including GluA1 (Lee et al 2017). NP1 negatively regulates mitochondrial function, transport and caspase activation through the intrinsic program of apoptosis pathway (Clayton et al., 2012) and negatively regulates excitatory synapse density (Figueiro-Silva et al., 2015). Since the expression of neuronal pentraxins is disrupted in AD brain and AD animal models (Abad et al., 2006, Bilousova et al., 2015, Cummings et al., 2017, Neuner et al., 2017), we investigated whether NP1 might serve as excitatory synapse derived plasma biomarker that is related to $A \beta$ and/or apoE isoform effects.

\section{Materials and methods}

Reagents and antibodies. All chemical reagents were purchased from Sigma-Aldrich, unless otherwise stated. Immunohistochemical and biochemical analyses utilized mouse monoclonal antibodies to Alix (Cell Signaling Technology Cat\# 2171S, RRID:AB_2299455), A 3 (6E10, Covance Research Products Inc Cat\# SIG-39320-200, RRID:AB_662798), drebrin (MBL International Cat\# D029-3, RRID:AB_591275), PSD-95 (UC Davis/NIH NeuroMab Facility Cat\# 75-028, RRID:AB_2307331), rabbit polyclonal antibodies to NP1 (Abgent Cat\# AP7272c, RRID:AB_2236168) and A (DAE, home-made (Lim et al., 2001)). Thromboplastin D was obtained from ThermoFisher 
(Middletown, VA). Recombinant NP1 was obtained from GenScript (Piscataway, $\mathrm{NJ})$.

Experimental animals. All animal procedures were approved by the Institutional Animal Care Use Committee of the Greater Los Angeles VA Healthcare System. EFAD transgenic (Tg) mice expressing 5 familial AD (FAD) mutations (Oakley et al., 2006) with human (h) APOE3 (E3FAD) or hAPOE4 (E4FAD), specifically $5 \times \mathrm{FAD}^{+/-} / \mathrm{APOE}^{+/+}$, were used for this study, as well as

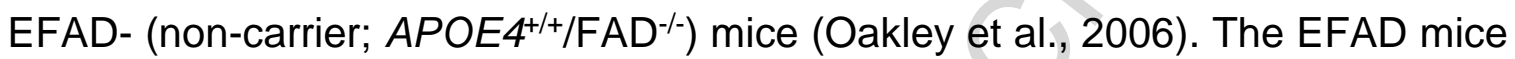
were developed by Dr. Mary Jo LaDu (Department of Anatomy and Cell Biology, University of Illinois at Chicago).

The effects of $A \beta$ on brain NP1 levels were also examined in wild-type (WT) B6129SF2 mice. At 4 months of age, these mice were implanted with intracerebroventricular (icv) pumps containing a solution of $A \beta 42$ oligomers (released at $50 \mathrm{ng} /$ hour) and human $\mathrm{HDL}(37 \mu \mathrm{g} / \mathrm{h}$, Calbiochem, CA; for $\mathrm{A} \beta$ oligomer stabilization) or HDL alone as previously described (Frautschy et al., 2001, Begum et al., 2008). All animals were infused for 2 weeks.

Laboratory mice were maintained on two basic diets. A standard breeder chow base diet (Mouse Diet PMI 5015, LabDiet) containing $11 \%$ fat and $0.18 \%$ omega-3 fatty acid as alpha linolenic acid was fed to EFAD, EFAD-, and WT mice that were used to characterize NP1 levels in brain, plasma, and plasma exosomes. Prior work suggests that excitatory synaptic marker loss and caspase activation are sensitive to dietary docosahexaenoic acid (DHA) supplementation (Calon et al., 2004, Calon et al., 2005). Therefore, separate cohorts of EFAD 
mice were assigned custom diets from 3 to 7 months of age: a DHA-depleting base diet containing $5 \%$ fat with high $n-6$ linoleic acid with or without DHA supplementation (Calon et al., 2004). These mice were divided into 4 treatment groups; E3FAD and E4FAD mice were fed the high $n-6$ polyunsaturated fatty acid (PUFA) diet either with or without $0.6 \%$ DHA (D; DHASCO oil, Martek, Columbia, MD).

Tissue preparation. At the conclusion of all experiments, mice were anesthetized with a lethal dose of pentobarbital $(100 \mathrm{mg} / \mathrm{kg})$ and perfused with a phosphate buffer with protease and phosphatase inhibitors as previously described (Calon et al., 2005). Brains were removed and one hemisphere was post-fixed in a formalin solution, sectioned by cryostat, and then used for immunohistochemical analyses. The other hemisphere was dissected and the hippocampal region was snap frozen in liquid nitrogen for subsequent biochemical analyses.

Exosome preparation. We used ultracentrifugation methods to prepare plasma exosome fractions. Plasma exosomes were isolated per published protocol. Briefly, plasma was diluted 1:5 with PBS containing protease and phosphatase inhibitors [PhosSTOP and cOmplete (Roche Diagnostics, Indianapois $(\mathrm{N})$ ], and then sequentially spun at $300 \times \mathrm{g}$ for 10 minutes at $4^{\circ} \mathrm{C}$, $2000 \times \mathrm{g}$ for 10 minutes at $4^{\circ} \mathrm{C}$, and $10,000 \times \mathrm{g}$ for 30 minutes at $4^{\circ} \mathrm{C}$ to remove cells and debris. The resulting supernatant was then centrifuged at $100,000 \times \mathrm{g}$ for 2 hours at $4^{\circ} \mathrm{C}$. The exosome pellet was subsequently resuspended in PBS with protease/phosphatase inhibitors prior to being snap frozen. 
Western blotting. Mouse hippocampal tissue was extracted into two fractions. Samples were initially sonicated in Tris-buffered saline (TBS) then centrifuged at $100,000 \times \mathrm{g}$ for 20 minutes at $4^{\circ} \mathrm{C}$. The resulting supernatant represents the soluble-cytosol (TBS) fraction. The remaining pellets were then sonicated in immunoprecipitation lysis buffer containing $1 \%$ Triton $\mathrm{X}-100,0.5 \%$ sodium deoxycholate, and $0.5 \%$ SDS and re-centrifuged at $100,000 \times \mathrm{g}$ for 20 minutes at $4^{\circ} \mathrm{C}$. This supernatant represents the membrano-cytoskeletal (lysis) fraction. Both the TBS and lysis buffers included protease and phosphatase inhibitors as previously described to prevent proteolysis and dephosphorylation of the tissue samples (Calon et al., 2004). For Western immunoblotting (WB), protein concentrations were determined using the Bio-Rad DC protein assay. Each sample contained $30 \mu \mathrm{g}$ of protein and was boiled in Laemmli sample buffer for 3 minutes prior to being loaded into a 34 lane $7-20 \%$ Tris-glycine gradient gel. Gels were electrophoresed, then transferred to Immobilon-P PVDF membranes (Millipore, Bedford, MA) as previously described (Ma et al., 2006). Blots were developed in the linear range with chemiluminescent detection and relative optical density on film scanned with a Biorad densitometer (Calon et al., 2004).

NP1 ELISA. Plasma NP1 levels were measured using a commerical ELISA kit (Aviva System Biology; human, OKDD0433, San Diego, CA) per the manufacturer's recommended protocol. Briefly, $100 \mu \mathrm{l}$ of serially titrated NP1 standards and two times diluted plasma samples were added into wells of the Anti-NP1 pre-coated micro-well plate. Two replicates of each standard and 
sample were used for the assay. The plate was incubated at RT for $2 \mathrm{hr}$ on a shaker plate. After washing with TBS, $100 \mu$ of biotinylated mouse anti-NP1 detector antibody was added and incubated at RT for $1 \mathrm{hr}$. Then, $100 \mu \mathrm{l}$ of Avidin-HRP conjugate was added and incubated for $1 \mathrm{hr}$. After washing with TBS, $90 \mu \mathrm{l}$ of TMB substrate was added and incubated for 20 minutes, then $50 \mu \mathrm{l}$ of stop solution was added and the absorbance was measured at $450 \mathrm{~nm}$. Plasma NP1 concentrations were then calculated from the standard curve. The $\%$ of CV cutoff was above $10 \%$, we excluded samples with CV's $>10 \%$ for data analysis.

Human Plasma. Human plasma samples from APOE-genotyped cognitively normal elderly $(\mathrm{NC}, \mathrm{n}=31)$ and patients with mild cognitive impairment $(\mathrm{MCl}, \mathrm{n}=33$ ) were obtained from the ImaGene Study (Ramirez et al., 2016) conducted through the UCLA Easton Alzheimer Center. Over three years of longitudinal follow-up during this study, a subset of $\mathrm{MCl}$ subjects subsequently progressed to probable mild $A D$ dementia $(E A D ; n=11)$; the remainder continued to meet diagnostic criteria for $\mathrm{MCl}(\mathrm{MCl} ; \mathrm{n}=22)$.

Statistical analysis. Analyses of biochemical and immunohistochemical data were performed using StatView 5.0 software. Group differences were compared using t-tests or analysis of variance (ANOVA). Post hoc comparisons were performed using Fisher LSD where appropriate.

\section{Results}


Plasma levels of NP1 and its fragments were increased in E4FAD mice and responded to DHA treatment. WB data for plasma levels of NP1 and its associated fragments are shown in Figure 1. The two primary NP1 species identified by WB in EFAD mouse plasma were a full-length band at $\sim 50 \mathrm{kDa}$ and a shorter fragment at $\sim 38 \mathrm{kDa}$ (Figure $1 \mathrm{~A}$, center lane). While both of these bands were also seen in the lane loaded with recombinant NP1 protein (Figure 1A, left lane), they were not seen in plasma from NP1 knockout mice (Figure 1A, right lane; gift from M. A. Hossein, Kennedy Kreiger Institute, Johns Hopkins University), suggesting that the $\sim 50 \mathrm{kDa}$ and $\sim 38 \mathrm{kDa}$ bands visualized on WB are NP1 specific.

A representative WB for NP1 in plasma samples from 7 8-month-old E4FAD and E3FAD mice is shown in Figure 1B. Quantitative analyses indicated that E4FAD mice had significantly higher levels of both full-length NP1 (Figure $1 \mathrm{~B} ; p<0.001)$ and the $\sim 38 \mathrm{kDa}$ NP1 fragment (Figure 1C; $p<0.01$ ) than E3FAD mice. Plasma levels of the $\sim 50 \mathrm{kDa}$ and $\sim 38 \mathrm{kDa}$ NP1 species were closely correlated (Figure 1D; $r^{2}=0.795, p<0.001$ ).

Prior work from our group has also shown that dietary DHA supplementation ameliorates excitatory synaptic pathology in Tg2576 mice (Calon et al., 2004, Calon et al., 2005). Since plasma NP1 species represent potential peripheral biomarkers of synaptic dysfunction, we examined the effects of DHA supplementation on these markers in E3FAD and E4FAD mice. E4FAD mice maintained on the DHA-supplemented diet from 3 to $7 \sim 8$ months of age had significantly lower levels of full-length NP1 (Figure $1 \mathrm{~B} ; p<0.01$ ) and the $\sim 38 \mathrm{kDa}$ 
NP1 fragment (Figure $1 C ; p<0.05$ ) relative to E4FAD mice maintained on the DHA-depleted diet. Plasma levels of each of these markers in DHAsupplemented E4FAD mice approximated those seen in E3FAD mice.

Hippocampal NP1 levels were increased in E4FAD mice and responded to DHA treatment. We subsequently sought to determine whether these observed changes in the levels plasma NP1 species reflected changes in hippocampal NP1 expression. WB data for NP1 levels in E3FAD and E4FAD hippocampus are shown in Figure 2. Full length NP1 levels were numerically higher in E4FAD versus E3FAD mice, but this difference fell short of statistical significance (Figure $2 A ; p=0.098)$. Significantly higher levels of the $\sim 38 \mathrm{kDa}$ NP1 fragment were seen in E4FAD versus E3FAD mice (Figure 2B; $p<0.01$ ). Dietary DHA supplementation treatment in E4FAD mice significantly reduced both the fulllength (Figure $2 \mathrm{~A} ; p<0.05$ ) and $\sim 38 \mathrm{kDa}$ (Figure 2B; $p<0.01$ ) NP1 species to levels comparable to those seen in the E3FAD mice. Furthermore, across all E4FAD animals, hippocampal levels of full-length NP1 were significantly correlated with plasma levels of both the full-length (Figure $2 \mathrm{C} ; r^{2}=0.538$, $p=0.002$ ) and $\sim 38 \mathrm{kDa}$ (Figure 2D; $\mathrm{r}^{2}=0.269, p=0.048$ ) NP1 species.

Elevations of plasma and brain NP1 levels in E4FAD mice were FAD transgene dependent. We subsequent sought to determine the relative effects of APOE4 expression and A $\beta$ overproduction on plasma and brain NP1 levels. Figure 3 illustrates relative plasma NP1 levels in E4FAD and E4FAD- mice. While differences in plasma levels of full-length NP1 between E4FAD and E4FAD- mice failed to reach statistical significance (Figure $3 A ; p>0.05$ ), the 
E4FAD mice had significantly higher plasma levels of the $38 \mathrm{kDa}$ NP1 fragment (Figure 3B; $p=0.05$ ). Immunohistochemical analyses were used to compare brain NP1 expression between E4FAD and E4FAD- mice (Figure 4). Confocal imaging in 7-month-old mice demonstrated increased cortical NP1 expression in E4FAD mice relative to E4FAD- mice (Figure 4A). Likewise, hippocampal NP1 levels were significantly higher in E4FAD mice (Figures 4B and 4C; $p<0.001$ ). Taken together these data suggest that both $A P O E$ genotype and $A \beta$ overproduction may contribute to increased central and peripheral NP1 levels.

A 42 oligomer infusions increased brain NP1 expression in wild type mice. Since the mutant APP and PS1 transgenes that are overexpressed in EFAD mice may have effects beyond $A \beta$ overproduction, we sought to confirm the effects of $A \beta$ on brain NP1 expression using icv infusions in wild type (WT) mice. $A \beta$ was infused as a solution of $A \beta 42$ oligomers (oA $\beta)$, which represent an important toxic $A \beta$ species that contributes to synaptic and cognitive deficits (Gong and lqbal, 2008, Danysz and Parsons, 2012, Ma et al., 2013). Figure 5 shows representative hippocampal $A \beta$ and NP1 staining after 2 weeks of $o A \beta$ or vehicle infusion into the right ventricles of 4-month-old WT mice. Infusions of oA $\beta$ increased deposition of both $A \beta$ (Figure $5 A$ ) and NP1 (Figure 5B). These results confirm prior work in neuronal cell culture indicating that $A \beta$ can induce NP1 expression (Abad et al., 2006). 
Plasma NP1 levels were elevated in patients with mild cognitive impairment $(M C l)$ and in cases of early-stage $A D$ that had progressed from $\mathrm{MCl}(E A D)$. Previous work has indicated that brain NP1 levels are increased in both APP/PS1 mice and human patients with sporadic late-onset AD (Abad et al., 2006). Therefore, we examined whether the plasma NP1 elevations seen in E4FAD mice would be detectable in human plasma samples. Because NP1 is enriched in excitatory synapses that are lost with AD progression (Mota et al., 2014) and transgenic rodent models of $A D$ are thought to represent very early stages of disease progression (Ashe, 2005), we focused on plasma samples from $\mathrm{MCl}$, including those that subsequently progressed to mild $A D$ dementia, and age-matched cognitively normal elderly (NC). Sandwich ELISA analysis of plasma NP1 demonstrated significantly higher levels in patients with $\mathrm{MCl}(p<$ 0.05 , Figure $6 A)$ and even higher levels in early-stage $A D(p<0.001$, Figure $6 A)$ relative to age-matched cognitively normal elderly. In our small early $A D$ subgroup, NP1 also showed a trend for an increase in APOE4 carriers compared to APOE4 non-carriers ( $p=0.078$, Fig $6 \mathrm{~B})$. While these results require confirmation with a much larger sample, they support the hypothesis that increased plasma NP1 levels may reflect early excitatory synapse loss in $\mathrm{MCl}$ and early $A D$, and are modulated by the APOE4 genotype with progressive disease.

Plasma NP1 was enriched in plasma exosome fractions from E4FAD mice. It remains uncertain how synapse-specific proteins such as NP1 are 
transported from the brain to the plasma. One potential mechanism is via exosomes. Prior work has shown that NP1 is present in human CSF exosomeenriched extracellular vesicles (EVs) (Chiasserini et al., 2014). We investigated whether NP1 is present in plasma EVs. EVs were isolated from pooled plasma of E4FAD mice and probed by WB for NP1 (Figure 7). We compared two independent pooled plasma samples from E4FAD mice ( $n=4 /$ group). Figure 7 demonstrates the relative enrichment of NP1 in plasma EV fractions (which contain the exosome marker ALIX) relative to whole plasma and postultracentrifugation supernatant fractions. These results suggest that NP1 may be exported from brain via exosomes or other extracellular vesicles, though we cannot rule out the possibility that NP1 may merely represent a contaminant within exosome-enriched fractions.

\section{Discussion}

The purpose of this study was to determine whether brain and/or plasma levels of NP1 reflect A $\beta$ - and APOE4-associated synaptic deficits in animal models of $A D$, as well as in $\mathrm{MCl}$ and probable $A D$ dementia cases. In the experiments described above, we demonstrate that the expression of both full length NP1 ( 50 kDa) and a $38 \mathrm{kDa}$ NP1 fragment were increased in a correlated fashion between hippocampal and plasma samples from E4FAD mice compared to E3FAD mice. Brain and plasma NP1 levels appear to reflect treatable synaptic dysfunction, as dietary DHA supplementation resulted in increased expression of excitatory synaptic markers and decreased expression of NP1 in E4FAD mice. 
As suggested by prior work (Abad et al., 2006), increased plasma and brain NP1 levels appear to be mediated in part through increased $A \beta$ expression. Furthermore, plasma NP1 levels were also increased in patients with $\mathrm{MCl}$ (particularly those who subsequently progressed to $A D$ dementia) relative to cognitively normal elderly. Within the small progressive MCl subgroup, NP1 levels were marginally higher in APOE4 carriers relative to non-carriers. Taken together, these data indicate that plasma NP1 species may serve as potential A $\beta$ and APOE4-dependent biomarkers of early synaptic dysfunction in AD. Although the precise mechanism by which these NP1 species reach the plasma remains uncertain, they may be trafficked from the brain via extracellular vesicles, possibly exosomes, after endocytosis and processing.

NP1 is one of a family of neuronal pentraxins (NPs) that appear to play important roles in both synaptic remodeling and neuronal apoptosis. NP1 is predominantly expressed in neurons at high concentrations in the hippocampus, cerebellum, and cerebral cortex (Schlimgen et al., 1995). NP1 is enriched at excitatory synapses and functions closely associated with NP2 (Narp) and AMPARs. NP1 interacts with the N-terminal domain of the AMPA receptor GluA4 subunit to mediate GluA4 synaptic recruitment (Sia et al., 2007). NP1 and NP2 form heterocomplexes that are required in vivo for the normal development of AMPAR-mediated transmission and function in developmental and activitydependent synaptic plasticity (Xu et al., 2003, Sia et al., 2007, Koch and Ullian, 2010). NPR and NP1 interact directly with GluA1 and increase GluA1 currents and puncta intensity; this adds support to a model in which NPR recruits and 
stabilizes NP1 and NP2 on the presynaptic plasma membrane where NPR acts in excitatory synapse assembly by binding to the N-terminal domain of AMPARs (Lee et al., 2017). Moreover, NP1 regulates the surface expression of the Kv7.2 subunit of the Kv7 family of potassium channels that control neuronal excitability (Figueiro-Silva et al., 2015). In mature neurons, NP1 negatively regulates excitatory density and synaptic plasticity (Figueiro-Silva et al., 2015), a process known to be $A \beta$ oligomer sensitive (Guntupalli et al., 2016). Elevations in NP1 can be seen in a number of pro-apoptotic conditions (DeGregorio-Rocasolano et al., 2001, Hossain et al., 2004, Enguita et al., 2005) and contribute to mitochondrial damage and neuronal death (Clayton et al., 2012, Al Rahim et al., 2013).

Prior work suggests that NP1 facilitates neurodegeneration in AD, as its expression is increased in dystrophic neurites around plaques in postmortem $A D$ brain and in transgenic AD mice (Abad et al., 2006, Cummings et al., 2017, Neuner et al., 2017). Cell culture studies suggest that $A \beta$-associated neuronal apoptosis is mediated through GSK-3 $\beta$ induced increases in NP1 expression (Abad et al., 2006, Russell et al., 2011). Our findings that NP1 levels were significantly higher in the brain of E4FAD mice relative to E4FAD- mice, and in WT mice infused with $A \beta 42$ relative to vehicle, confirm the relationship between $A \beta$ and NP1 and raise the possibility that plasma NP1 levels reflect the downstream effects of cerebral $A \beta$ neurotoxicity. In human study, we found plasma NP1 levels were significantly elevated in $M C l$ and early $A D$, suggesting that the alteration of CSF and/or plasma NP1 might be independent on NP2 and 
also disease-stage dependent reflecting synaptic pathology. Less NP1 elevation observed in $A D$ or later stages of $A D$ might be caused by extensive loss of its synaptic sources (Llano et al., 2017, Brinkmalm et al., 2018).

In our study with a small subgroup, we found that plasma NP1 had a trend increase in the subjects with $A P O E 4$ carriers who had recently progressed from $\mathrm{MCl}$ to $\mathrm{AD}$ dementia. Similarly, our animal study shows higher brain and plasma NP1 levels in E4FAD versus E3FAD mice. These data suggesting that APOE4associated synaptic dysfunction (Klein et al., 2010) may closely link to NP1 dysfunction. The $A P O E \varepsilon 4$ allele is the major genetic risk factor for the late onset AD (Corder et al., 1993, Kim et al., 2009). While some of this increased risk appears to be mediated through A $\beta$-associated mechanisms (Christensen et al., 2010, Hashimoto et al., 2012, Koffie et al., 2012), other APOE4-associated effects on dendritic spine density and morphology (Dumanis et al., 2009, Klein et al., 2010), glutamate receptor function and reelin-induced enhancement of longterm potentiation (Chen et al., 2010) appear to be independent of (and synergistic with) $A \beta$ pathophysiology. Prior work with $E F A D$ - mice has shown impaired synaptic plasticity (Trommer et al., 2004) and decreased expression of synaptic markers such as drebrin (Nwabuisi-Heath et al., 2014) in APOE4-TR versus $A P O E 3-T R$ animals.

Prior work from our group and others has demonstrated that DHA supplementation protects against $A \beta$-associated depletion of synaptic markers such as drebrin, NR2B and PSD-95 in Tg2576 mice (Calon et al., 2004, Calon et al., 2005) and drebrin in APPsw/PS1 $\Delta \mathrm{E} 9$ mice (Perez et al., 2010). DHA 
supplementation in the current study in E4FAD mice showed reduced brain and plasma levels of NP1 species. While DHA treatment has not been shown to improve outcomes in mild-to-moderate $A D$ dementia patients who carry an APOE4 allele (Quinn et al., 2010), it does appear to have beneficial effects on MCl (Sinn et al., 2012, Lee et al., 2013, Bo et al., 2017). Furthermore, recent data indicate that increased consumption of seafood (which has high DHA levels) is associated with decreased AD neuropathology in APOE4 carriers (Morris et al., 2016).

Although it remains uncertain how NP1 may be transported from brain to plasma, we observed that NP1 (both full length and a $38 \mathrm{kDa}$ fragment) were found in plasma exosome enriched fractions in animals. This is consistent with the presence of NP1 peptides in extracellular vesicle (EV)/exosome fractions isolated from pooled samples of human CSF (Chiasserini et al., 2014). Exosomes are small vesicles derived from the multivesicular bodies (MVBs) of the endocytic pathways that can cross the blood-brain barrier (Zhuang et al., 2011, Kalani et al., 2014, Andras and Toborek, 2016). Since NP1 interacts with AMPA-type glutamate receptors that participate in excitatory synaptic transmission involved in learning and memory, and neural exosomes contain GluR2/3 subunits of glutamate receptors (Faure et al., 2006), the detection NP1 species in exosome-enriched plasma fractions may reflect alterations in AMPA receptor function or expression during early stages of AD pathophysiology. The independently regulated NP2 is also found in plasma neural exosomes where it was recently reported to be decreased in AD along with GluA4 (Goetzl et al., 
2017).

However, there are a number of limitations to using plasma NP1 as a specific biomarker for AD. First, hypoxic-ischemic injury can induce NP1 expression (Hossain et al., 2004). Second, although NP1 is thought to be exclusively expressed in brain and was not detected in heart, skeletal muscle, placenta, lung, liver, pancreas, or kidney samples from humans, rats, and mice (Hsu and Perin, 1995, Omeis et al., 1996), it remains possible that a portion of the NP1 found in plasma might be derived from heretofore unexamined peripheral sources. Third, only a small subgroup of human $\mathrm{MCl}$ patients progressed to mild $A D$ dementia represents. While there was a trend towards higher plasma NP1 levels amongst APOE4 carriers versus non-carriers in this subgroup, this finding needs to be validated with a much larger sample size.

\section{Conclusion}

We found that NP1 species were significantly increased in both plasma and brain samples of E4FAD mice in a correlated fashion. NP1 species were also increased in human plasma samples from patients diagnosed with $\mathrm{MCl}$ (particularly those who subsequently progressed to $A D$ dementia) relative to cognitively normal elderly. These elevations of NP1 at earlier stages of AD pathophysiology may parallel the process of synapse loss. In E4FAD mice, these increases in NP1 were ameliorated by dietary DHA supplementation. Since NP1 may be involved in progressive excitatory synapse loss associated with $A \beta$ and APOE4, our findings suggest that NP1 may represent a potential plasma 
biomarker for excitatory synaptic dysfunction in $\mathrm{MCl}$ and early $\mathrm{AD}$, which could be used to monitor disease progression and/or response to therapeutic interventions.

\section{Figure legends}

Figure 1. Plasma NP1 species are increased in E4FAD mice and reduced by dietary DHA supplementation. A. Both $50 \mathrm{kDa}$ NP1 band and 38 kDa NP1 reactive fragments were absent in NP1 KO mice plasma, mouse IgG control and secondary (2nd) antibody alone lanes, but present in the NP1 recombinant protein loading lane, suggesting that these are NP1 specific reactive bands. Western blot analysis showed that plasma $50 \mathrm{kDa}$ NP1 $(p<0.001$, B), a $38 \mathrm{kDa}$ NP1 reactive fragment $(p<0.01, \mathbf{B}, \mathbf{C})$ were significantly increased in 7-8 monthold E4FAD mice compared to age-matched E3FAD mice. After EFAD mice were treated by $0.6 \%$ DHA from 3 to $7 \sim 8$ months, DHA significantly reduced $50 \mathrm{kDa}(p$ $<0.01, \mathrm{~B})$ and $38 \mathrm{kDa}$ NP1 species $(p<0.05, \mathrm{C})$ in E4FAD mice, but not in E3FAD mice. D. The plasma $50 \mathrm{kDa} N P 1$ and $38 \mathrm{kDa}$ NP1 fragments were significantly correlated $\left(R^{\wedge} 2=.795, p<0.0001\right)$. Error bars represent + s.e.m. ${ }^{*} p<0.05 ;{ }^{* *} p<0.01 ;{ }^{* * *} p<0.001 ;{ }^{* * *} p<0.0001$, one-way ANOVA test. In this figure, E3 indicates E3FAD mice and E4 indicates E4FAD mice. +D indicates DHA treated groups.

Figure 2. Brain NP1 species, are increased in E4FAD mice and reduced by dietary DHA supplementation; brain and plasma NP1 levels are correlated in E4FAD mice. 
A. Western blot analysis showed a trend to an increase in $50 \mathrm{kDa}$ NP1 band ( $p=$ 0.098, NS) in E4FAD mice compared to E3FAD mice, while DHA treatment significantly reduced it in DHA-treated E4FAD mice compared to untreated E4FAD mice $(p<0.05)$. B. $38 \mathrm{kDa} N P 1$ fragments were increased in E4FAD mice compared to E3FAD mice, $(p<0.01)$, while DHA treatment significantly reduced $38 \mathrm{kDa} \mathrm{NP} 1$ fragment in DHA-treated E4FAD mice compared to untreated E4FAD mice $(p<0.01)$. C. Brain $50 \mathrm{kDa}$ NP1 significantly correlated with plasma $50 \mathrm{kDa}$ NP1 in E4FAD mice $\left(\mathrm{R}^{2}=0.538, p=0.002\right)$. D. Brain 50 kDa NP1 was also significantly correlated with plasma levels of the $38 \mathrm{kDa} N P 1$ fragment in E4FAD mice $\left(R^{2}=0.269, p=0.048\right)$. In this figure, E3 indicates E3FAD mice and E4 indicates E4FAD mice. +D indicates DHA treated groups.

Figure 3. The elevation of Plasma NP1 in E4FAD mice is FAD transgene dependent. A. Western blot analysis showed no statistical significance differences in plasma $50 \mathrm{kDa} N \mathrm{NP} 1$ band in E4FAD mice compared to E4FADmice ( $p>0.05$, with both on 5015 diet). B. Western blot analysis showed increases in plasma $38 \mathrm{kDa}$ NP1 fragment in E4FAD mice compared to E4FADmice $(p=0.05)$.

Figure 4. The elevation of brain NP1 in E4FAD mice is FAD transgene dependent. A. Immunohistochemistry by confocal imaging revealed brain cortex NP1 was increased in 7-month-old E4FAD mice compared to age-matched E4FAD- mice. B, C Quantification of brain hippocampal NP1 from DAB staining 
indicated that NP1 was significantly increased in E4FAD mice compared to E4FAD- mice $(p<0.0001)$ (with both on 5015 diet).

Figure 5. A 342 oligomers infusion increases brain NP1. After infusing $50 \mu \mathrm{g}$ of $A \beta 42$ oligomers $(O A \beta)$ into right ventricle of 4-month-old wile type (WT) mice over 2 weeks, brain adjacent serial sections were used for A $\beta$ and NP1 staining. A. $A \beta$ Deposition (red) was observed by immunostaining with anti-A $\beta$ antibody, DAE, in the dentate gyrus of the hippocampus in OA $\beta$-infused WT mice but not in the vehicle (Veh)-infused mice. B. NP1 (green) was increased in the dentate gyrus of the hippocampus in OAß-infused WT mice but not in the Veh-infused mice. Quantification of immunostained NP1 cells confirmed a significant difference between the two groups $(p<0.001)$.

Figure 6. Plasma NP1 levels are increased in $\mathrm{MCl}$ and early AD dementia. A. ELISA analysis showed that plasma NP1 was increased in patients with $\mathrm{MCl}(p<$ $0.05)$ and early $A D(E A D, p<0.01)$ relative to normal cognitive elderly $(N C)$. B. In the EAD group, NP1 showed a trend increases in APOE4 carriers $(E 4+)$ relative to non-APOE4 carriers (E4-).

Figure 7. Plasma NP1 and NP1 fragments are enriched in exosomes containing fractions isolated from pooled plasma of E4FAD mice.

Plasma extracellular vesicles were isolated from pooled plasma of human and E4FAD mice via ultracentrifugation. Western blot analysis revealed that NP1 
species were enriched in E4FAD plasma exosome enriched fractions. Western blot results demonstrated levels of NP1 and NP1 fragments in plasma before ultracentrifugation (pla, whole plasma) were reduced or depleted in the supernatant (sup) after pelleting of exosomes (Exo) using ultracentrifugation in two independent pooled plasma groups of E4FAD mice ( $n=4 /$ per group). NP1 and its fragments were enriched in the pellet extracellular vesicle fractions, which contain the exosome marker ALIX.

Acknowledgments: This work was supported by State of California Department of Public Health Alzheimer's Disease Program (RFA \#16-10054, QLM) , VA MERIT (BX000542, GMC), NIH RO1 (AT008916, GMC), NIH RO1 (AG13471, GMC), NIH R21 (AG050269, SAF), R01 AG040770 (LGA), K02 AG048240 (LGA), P50 AG16570 and the Easton Consortium for AD Drug Discovery and Biomarker Development (LGA and GMC).

\section{References}

Abad MA, Enguita M, DeGregorio-Rocasolano N, Ferrer I, Trullas R (2006) Neuronal pentraxin 1 contributes to the neuronal damage evoked by amyloid-beta and is overexpressed in dystrophic neurites in Alzheimer's brain. J Neurosci 26:12735-12747.

Al Rahim M, Thatipamula S, Hossain MA (2013) Critical role of neuronal pentraxin 1 in mitochondria-mediated hypoxic-ischemic neuronal injury. Neurobiol Dis 50:59-68.

Andras IE, Toborek M (2016) Extracellular vesicles of the blood-brain barrier. Tissue Barriers 4:e1131804.

Ashe KH (2005) Mechanisms of memory loss in Abeta and tau mouse models. Biochem Soc Trans 33:591-594.

Begum AN, Jones MR, Lim GP, Morihara T, Kim P, Heath DD, Rock CL, Pruitt MA, Yang F, Hudspeth B, Hu S, Faull KF, Teter B, Cole GM, Frautschy SA (2008) Curcumin structure-function, bioavailability, and efficacy in models of neuroinflammation and Alzheimer's disease. The Journal of pharmacology and experimental therapeutics 326:196-208.

Bilousova T, Taylor K, Emirzian A, Gylys R, Frautschy SA, Cole GM, Teng E (2015) Parallel age-associated changes in brain and plasma neuronal pentraxin receptor levels in a transgenic APP/PS1 rat model of Alzheimer's disease. Neurobiol Dis 74:32-40.

Bo Y, Zhang X, Wang Y, You J, Cui H, Zhu Y, Pang W, Liu W, Jiang Y, Lu Q (2017) The n-3 Polyunsaturated Fatty Acids Supplementation Improved the Cognitive 
Function in the Chinese Elderly with Mild Cognitive Impairment: A DoubleBlind Randomized Controlled Trial. Nutrients 9.

Brinkmalm G, Sjodin S, Simonsen AH, Hasselbalch SG, Zetterberg H, Brinkmalm A, Blennow K (2018) A Parallel Reaction Monitoring Mass Spectrometric Method for Analysis of Potential CSF Biomarkers for Alzheimer's Disease. Proteomics Clinical applications 12.

Bu G (2009) Apolipoprotein E and its receptors in Alzheimer's disease: pathways, pathogenesis and therapy. Nat Rev Neurosci 10:333-344.

Calon F, Lim GP, Morihara T, Yang F, Ubeda O, Salem N, Jr., Frautschy SA, Cole GM (2005) Dietary n-3 polyunsaturated fatty acid depletion activates caspases and decreases NMDA receptors in the brain of a transgenic mouse model of Alzheimer's disease. Eur J Neurosci 22:617-626.

Calon F, Lim GP, Yang F, Morihara T, Teter B, Ubeda O, Rostaing P, Triller A, Salem N, Jr., Ashe KH, Frautschy SA, Cole GM (2004) Docosahexaenoic acid protects from dendritic pathology in an Alzheimer's disease mouse model. Neuron 43:633-645.

Chen Y, Durakoglugil MS, Xian X, Herz J (2010) ApoE4 reduces glutamate receptor function and synaptic plasticity by selectively impairing ApoE receptor recycling. Proc Natl Acad Sci U S A 107:12011-12016.

Chiasserini D, van Weering JR, Piersma SR, Pham TV, Malekzadeh A, Teunissen CE, de Wit H, Jimenez CR (2014) Proteomic analysis of cerebrospinal fluid extracellular vesicles: a comprehensive dataset. J Proteomics 106:191-204.

Cho RW, Park JM, Wolff SB, Xu D, Hopf C, Kim JA, Reddy RC, Petralia RS, Perin MS, Linden DJ, Worley PF (2008) mGluR1/5-dependent long-term depression requires the regulated ectodomain cleavage of neuronal pentraxin NPR by TACE. Neuron 57:858-871.

Christensen DZ, Schneider-Axmann T, Lucassen PJ, Bayer TA, Wirths O (2010) Accumulation of intraneuronal Abeta correlates with ApoE4 genotype. Acta Neuropathol 119:555-566.

Clayton KB, Podlesniy P, Figueiro-Silva J, Lopez-Domenech G, Benitez L, Enguita M, Abad MA, Soriano E, Trullas R (2012) NP1 regulates neuronal activitydependent accumulation of BAX in mitochondria and mitochondrial dynamics. J Neurosci 32:1453-1466.

Corder EH, Saunders AM, Strittmatter WJ, Schmechel DE, Gaskell PC, Small GW, Roses AD, Haines JL, Pericak-Vance MA (1993) Gene dose of apolipoprotein E type 4 allele and the risk of Alzheimer's disease in late onset families. Science 261:921-923.

Cummings DM, Benway TA, Ho H, Tedoldi A, Fernandes Freitas MM, Shahab L, Murray CE, Richard-Loendt A, Brandner S, Lashley T, Salih DA, Edwards FA (2017) Neuronal and Peripheral Pentraxins Modify Glutamate Release and may Interact in Blood-Brain Barrier Failure. Cereb Cortex 27:3437-3448.

Danysz W, Parsons CG (2012) Alzheimer's disease, beta-amyloid, glutamate, NMDA receptors and memantine--searching for the connections. Br J Pharmacol 167:324-352. 
DeGregorio-Rocasolano N, Gasull T, Trullas R (2001) Overexpression of neuronal pentraxin 1 is involved in neuronal death evoked by low $\mathrm{K}(+)$ in cerebellar granule cells. J Biol Chem 276:796-803.

Dumanis SB, Tesoriero JA, Babus LW, Nguyen MT, Trotter JH, Ladu MJ, Weeber EJ, Turner RS, Xu B, Rebeck GW, Hoe HS (2009) ApoE4 decreases spine density and dendritic complexity in cortical neurons in vivo. J Neurosci 29:1531715322.

Enguita M, DeGregorio-Rocasolano N, Abad A, Trullas R (2005) Glycogen synthase kinase 3 activity mediates neuronal pentraxin 1 expression and cell death induced by potassium deprivation in cerebellar granule cells. Mol Pharmacol 67:1237-1246.

Faure J, Lachenal G, Court M, Hirrlinger J, Chatellard-Causse C, Blot B, Grange J, Schoehn G, Goldberg Y, Boyer V, Kirchhoff F, Raposo G, Garin J, Sadoul R (2006) Exosomes are released by cultured cortical neurones. Mol Cell Neurosci 31:642-648.

Figueiro-Silva J, Gruart A, Clayton KB, Podlesniy P, Abad MA, Gasull X, DelgadoGarcia JM, Trullas R (2015) Neuronal pentraxin 1 negatively regulates excitatory synapse density and synaptic plasticity. J Neurosci 35:5504-5521.

Frautschy SA, Hu W, Kim P, Miller SA, Chu T, Harris-White ME, Cole GM (2001) Phenolic anti-inflammatory antioxidant reversal of Abeta-induced cognitive deficits and neuropathology. Neurobiology of aging 22:993-1005.

Goetzl EJ, Abner EL, Jicha GA, Kapogiannis D, Schwartz JB (2017) Declining levels of functionally specialized synaptic proteins in plasma neuronal exosomes with progression of Alzheimer's disease. FASEB journal : official publication of the Federation of American Societies for Experimental Biology fj201700731R.

Gong CX, Iqbal K (2008) Hyperphosphorylation of microtubule-associated protein tau: a promising therapeutic target for Alzheimer disease. Curr Med Chem 15:2321-2328.

Guntupalli S, Widagdo J, Anggono V (2016) Amyloid-beta-Induced Dysregulation of AMPA Receptor Trafficking. Neural Plast 2016:3204519.

Hashimoto T, Serrano-Pozo A, Hori Y, Adams KW, Takeda S, Banerji AO, Mitani A, Joyner D, Thyssen DH, Bacskai BJ, Frosch MP, Spires-Jones TL, Finn MB, Holtzman DM, Hyman BT (2012) Apolipoprotein E, especially apolipoprotein E4, increases the oligomerization of amyloid beta peptide. J Neurosci 32:15181-15192.

Hossain MA, Russell JC, O'Brien R, Laterra J (2004) Neuronal pentraxin 1: a novel mediator of hypoxic-ischemic injury in neonatal brain. J Neurosci 24:41874196.

Hsu YC, Perin MS (1995) Human neuronal pentraxin II (NPTX2): conservation, genomic structure, and chromosomal localization. Genomics 28:220-227.

Hua X, Gutman B, Boyle CP, Rajagopalan P, Leow AD, Yanovsky I, Kumar AR, Toga AW, Jack CR, Jr., Schuff N, Alexander GE, Chen K, Reiman EM, Weiner MW, Thompson PM, Alzheimer's Disease Neuroimaging I (2011) Accurate measurement of brain changes in longitudinal MRI scans using tensor-based morphometry. Neuroimage 57:5-14. 
Hudry E, Dashkoff J, Roe AD, Takeda S, Koffie RM, Hashimoto T, Scheel M, SpiresJones T, Arbel-Ornath M, Betensky R, Davidson BL, Hyman BT (2013) Gene transfer of human Apoe isoforms results in differential modulation of amyloid deposition and neurotoxicity in mouse brain. Sci Transl Med 5:212ra161.

Jagust WJ, Landau SM, Alzheimer's Disease Neuroimaging I (2012) Apolipoprotein E, not fibrillar beta-amyloid, reduces cerebral glucose metabolism in normal aging. J Neurosci 32:18227-18233.

Kalani A, Tyagi A, Tyagi N (2014) Exosomes: mediators of neurodegeneration, neuroprotection and therapeutics. Mol Neurobiol 49:590-600.

Kim J, Basak JM, Holtzman DM (2009) The role of apolipoprotein E in Alzheimer's disease. Neuron 63:287-303.

Klein RC, Mace BE, Moore SD, Sullivan PM (2010) Progressive loss of synaptic integrity in human apolipoprotein E4 targeted replacement mice and attenuation by apolipoprotein E2. Neuroscience 171:1265-1272.

Koch SM, Ullian EM (2010) Neuronal pentraxins mediate silent synapse conversion in the developing visual system. J Neurosci 30:5404-5414.

Koffie RM, Hashimoto T, Tai HC, Kay KR, Serrano-Pozo A, Joyner D, Hou S, Kopeikina KJ, Frosch MP, Lee VM, Holtzman DM, Hyman BT, Spires-Jones TL (2012) Apolipoprotein E4 effects in Alzheimer's disease are mediated by synaptotoxic oligomeric amyloid-beta. Brain 135:2155-2168.

Lee LK, Shahar S, Chin AV, Yusoff NA (2013) Docosahexaenoic acid-concentrated fish oil supplementation in subjects with mild cognitive impairment (MCI): a 12-month randomised, double-blind, placebo-controlled trial. Psychopharmacology (Berl) 225:605-612.

Lee SJ, Wei M, Zhang C, Maxeiner S, Pak C, Calado Botelho S, Trotter J, Sterky FH, Sudhof TC (2017) Presynaptic Neuronal Pentraxin Receptor Organizes Excitatory and Inhibitory Synapses. J Neurosci 37:1062-1080.

Li S, Jin M, Koeglsperger T, Shepardson NE, Shankar GM, Selkoe DJ (2011) Soluble Abeta oligomers inhibit long-term potentiation through a mechanism involving excessive activation of extrasynaptic NR2B-containing NMDA receptors. J Neurosci 31:6627-6638.

Lim GP, Chu T, Yang F, Beech W, Frautschy SA, Cole GM (2001) The curry spice curcumin reduces oxidative damage and amyloid pathology in an Alzheimer transgenic mouse. J Neurosci 21:8370-8377.

Llano DA, Bundela S, Mudar RA, Devanarayan V, Alzheimer's Disease Neuroimaging I (2017) A multivariate predictive modeling approach reveals a novel CSF peptide signature for both Alzheimer's Disease state classification and for predicting future disease progression. PloS one 12:e0182098.

Ma QL, Lim GP, Harris-White ME, Yang F, Ambegaokar SS, Ubeda OJ, Glabe CG, Teter B, Frautschy SA, Cole GM (2006) Antibodies against beta-amyloid reduce Abeta oligomers, glycogen synthase kinase-3beta activation and tau phosphorylation in vivo and in vitro. J Neurosci Res 83:374-384.

Ma QL, Zuo X, Yang F, Ubeda OJ, Gant DJ, Alaverdyan M, Teng E, Hu S, Chen PP, Maiti P, Teter B, Cole GM, Frautschy SA (2013) Curcumin suppresses soluble tau 
dimers and corrects molecular chaperone, synaptic, and behavioral deficits in aged human tau transgenic mice. J Biol Chem 288:4056-4065.

Morris MC, Brockman J, Schneider JA, Wang Y, Bennett DA, Tangney CC, van de Rest $O$ (2016) Association of Seafood Consumption, Brain Mercury Level, and APOE epsilon4 Status With Brain Neuropathology in Older Adults. JAMA 315:489-497.

Mota SI, Ferreira IL, Rego AC (2014) Dysfunctional synapse in Alzheimer's disease A focus on NMDA receptors. Neuropharmacology 76 Pt A:16-26.

Neuner SM, Wilmott LA, Hoffmann BR, Mozhui K, Kaczorowski CC (2017) Hippocampal proteomics defines pathways associated with memory decline and resilience in normal aging and Alzheimer's disease mouse models. Behav Brain Res 322:288-298.

Nwabuisi-Heath E, Rebeck GW, Ladu MJ, Yu C (2014) ApoE4 delays dendritic spine formation during neuron development and accelerates loss of mature spines in vitro. ASN Neuro 6:e00134.

Oakley H, Cole SL, Logan S, Maus E, Shao P, Craft J, Guillozet-Bongaarts A, Ohno M, Disterhoft J, Van Eldik L, Berry R, Vassar R (2006) Intraneuronal betaamyloid aggregates, neurodegeneration, and neuron loss in transgenic mice with five familial Alzheimer's disease mutations: potential factors in amyloid plaque formation. J Neurosci 26:10129-10140.

Omeis IA, Hsu YC, Perin MS (1996) Mouse and human neuronal pentraxin 1 (NPTX1): conservation, genomic structure, and chromosomal localization. Genomics 36:543-545.

Perez SE, Berg BM, Moore KA, He B, Counts SE, Fritz JJ, Hu YS, Lazarov O, Lah JJ, Mufson EJ (2010) DHA diet reduces AD pathology in young APPswe/PS1 Delta E9 transgenic mice: possible gender effects. J Neurosci Res 88:10261040.

Quinn JF, Raman R, Thomas RG, Yurko-Mauro K, Nelson EB, Van Dyck C, Galvin JE, Emond J, Jack CR, Jr., Weiner M, Shinto L, Aisen PS (2010) Docosahexaenoic acid supplementation and cognitive decline in Alzheimer disease: a randomized trial. JAMA 304:1903-1911.

Ramirez LM, Goukasian N, Porat S, Hwang KS, Eastman JA, Hurtz S, Wang B, Vang N, Sears R, Klein E, Coppola G, Apostolova LG (2016) Common variants in ABCA7 and MS4A6A are associated with cortical and hippocampal atrophy. Neurobiol Aging 39:82-89.

Reiman EM, Chen K, Alexander GE, Caselli RJ, Bandy D, Osborne D, Saunders AM, Hardy J (2004) Functional brain abnormalities in young adults at genetic risk for late-onset Alzheimer's dementia. Proc Natl Acad Sci U S A 101:284-289.

Russell JC, Kishimoto K, O'Driscoll C, Hossain MA (2011) Neuronal pentraxin 1 induction in hypoxic-ischemic neuronal death is regulated via a glycogen synthase kinase-3alpha/beta dependent mechanism. Cell Signal 23:673-682.

Schlimgen AK, Helms JA, Vogel H, Perin MS (1995) Neuronal pentraxin, a secreted protein with homology to acute phase proteins of the immune system. Neuron 14:519-526.

Shankar GM, Bloodgood BL, Townsend M, Walsh DM, Selkoe DJ, Sabatini BL (2007) Natural oligomers of the Alzheimer amyloid-beta protein induce reversible 
synapse loss by modulating an NMDA-type glutamate receptor-dependent signaling pathway. J Neurosci 27:2866-2875.

Shi L, Du X, Zhou H, Tao C, Liu Y, Meng F, Wu G, Xiong Y, Xia C, Wang Y, Bi G, Zhou JN (2014) Cumulative effects of the ApoE genotype and gender on the synaptic proteome and oxidative stress in the mouse brain. Int J

Neuropsychopharmacol 17:1863-1879.

Sia GM, Beique JC, Rumbaugh G, Cho R, Worley PF, Huganir RL (2007) Interaction of the N-terminal domain of the AMPA receptor GluR4 subunit with the neuronal pentraxin NP1 mediates GluR4 synaptic recruitment. Neuron 55:87-102.

Sinn N, Milte CM, Street SJ, Buckley JD, Coates AM, Petkov J, Howe PR (2012) Effects of n-3 fatty acids, EPA v. DHA, on depressive symptoms, quality of life, memory and executive function in older adults with mild cognitive impairment: a 6-month randomised controlled trial. Br J Nutr 107:16821693.

Snyder EM, Nong Y, Almeida CG, Paul S, Moran T, Choi EY, Nairn AC, Salter MW, Lombroso PJ, Gouras GK, Greengard P (2005) Regulation of NMDA receptor trafficking by amyloid-beta. Nat Neurosci 8:1051-1058.

Terry RD, Masliah E, Salmon DP, Butters N, DeTeresa R, Hill R, Hansen LA, Katzman $R$ (1991) Physical basis of cognitive alterations in Alzheimer's disease: synapse loss is the major correlate of cognitive impairment. Ann Neurol 30:572-580.

Tomic JL, Pensalfini A, Head E, Glabe CG (2009) Soluble fibrillar oligomer levels are elevated in Alzheimer's disease brain and correlate with cognitive dysfunction. Neurobiol Dis 35:352-358.

Trommer BL, Shah C, Yun SH, Gamkrelidze G, Pasternak ES, Ye GL, Sotak M, Sullivan PM, Pasternak JF, LaDu MJ (2004) ApoE isoform affects LTP in human targeted replacement mice. Neuroreport 15:2655-2658.

Xu D, Hopf C, Reddy R, Cho RW, Guo L, Lanahan A, Petralia RS, Wenthold RJ, O'Brien RJ, Worley P (2003) Narp and NP1 form heterocomplexes that function in developmental and activity-dependent synaptic plasticity. Neuron 39:513528.

Zhuang X, Xiang X, Grizzle W, Sun D, Zhang S, Axtell RC, Ju S, Mu J, Zhang L, Steinman L, Miller D, Zhang HG (2011) Treatment of brain inflammatory diseases by delivering exosome encapsulated anti-inflammatory drugs from the nasal region to the brain. Mol Ther 19:1769-1779. 


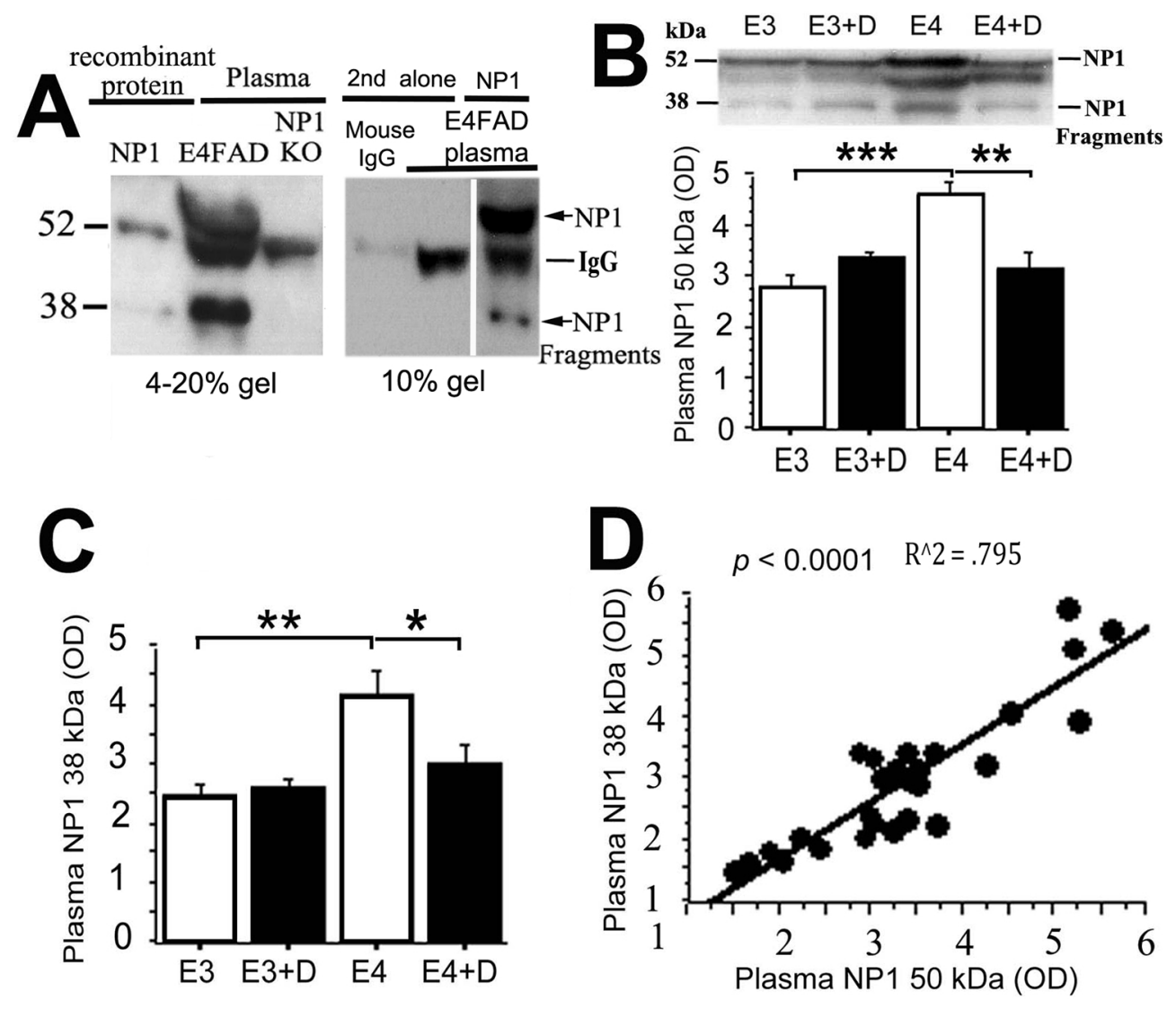

Figure 1 


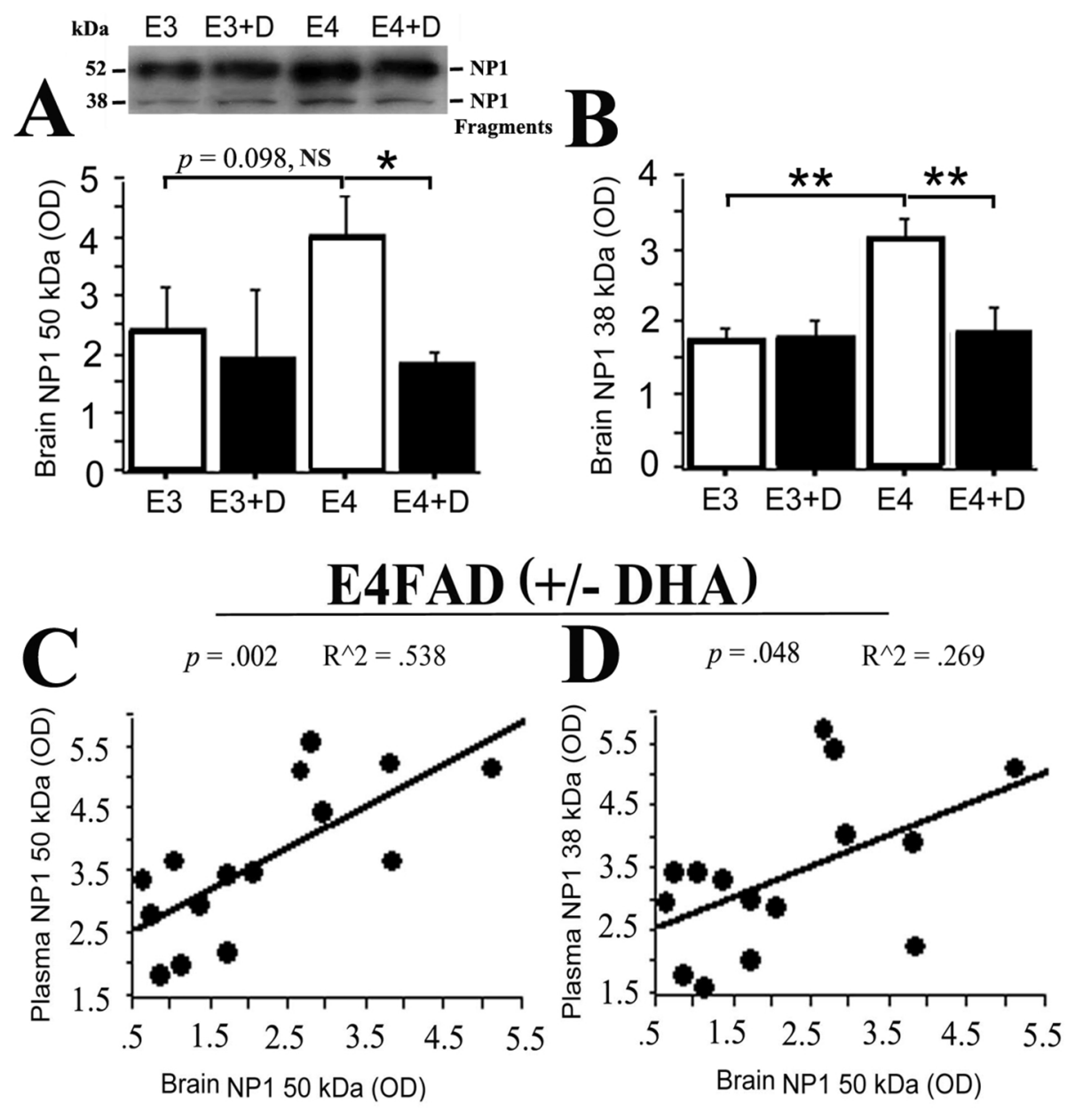

Figure 2 
kDa EAFAD+ EAFAD-

A ${ }^{52-}$

- NP1
- NP1

fragments

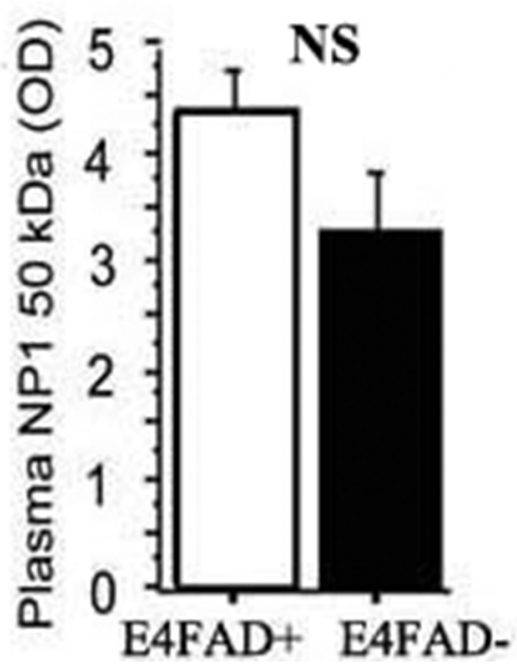

B

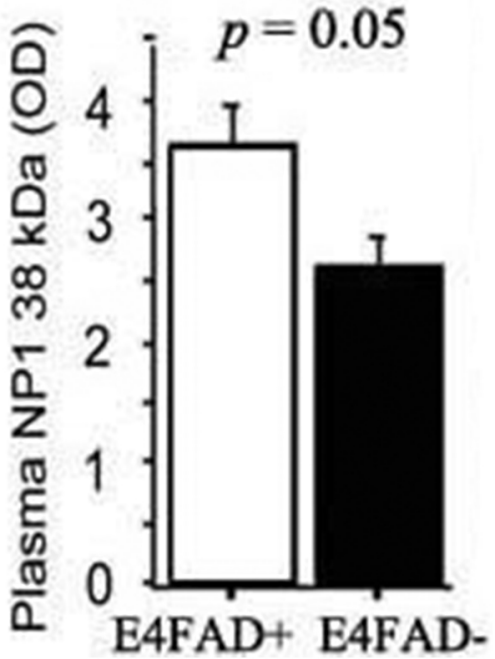

Figure 3 


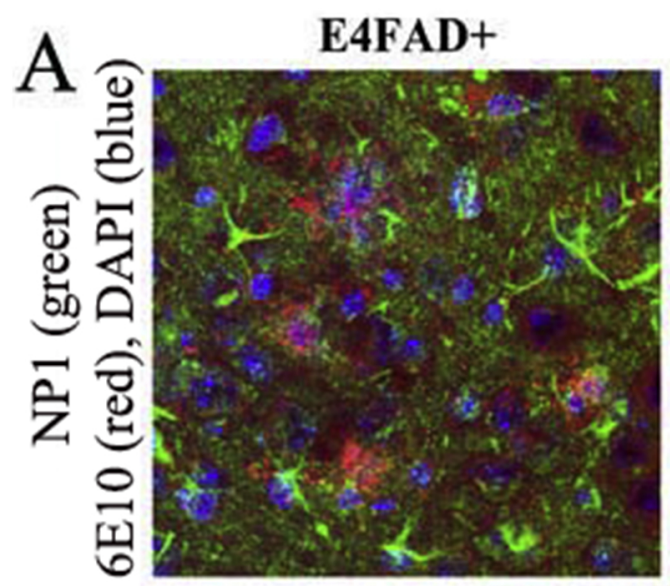

E4FAD-
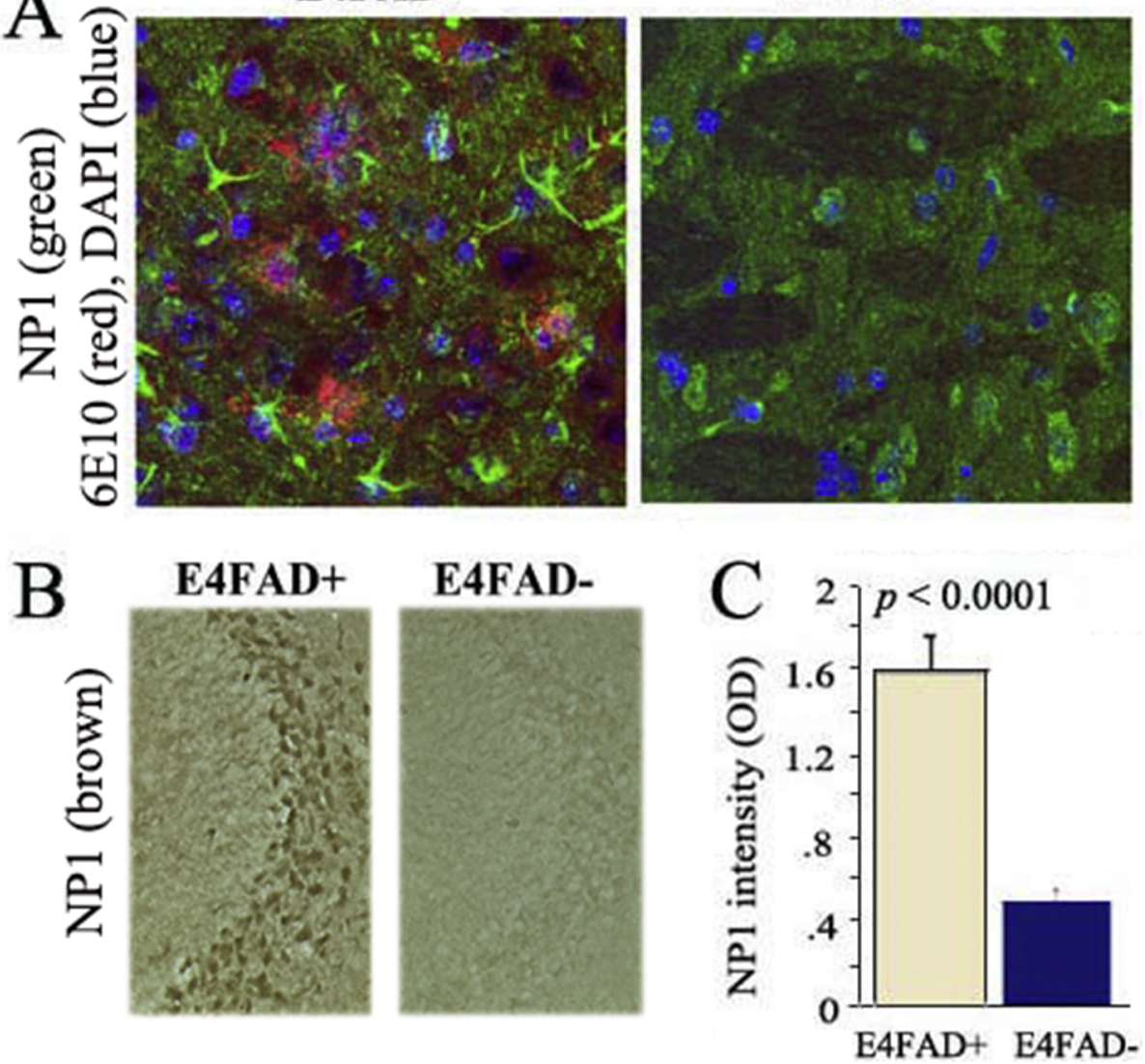

Figure 4 
A

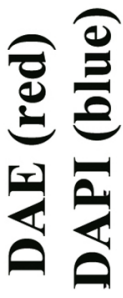

B

$\begin{array}{ll}2 & 0 \\ 0 & 0 \\ 0 & 0 \\ 2 & 0 \\ 2 & 0\end{array}$

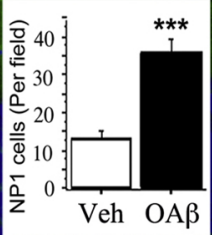

Figure 5 


\section{ELISA}
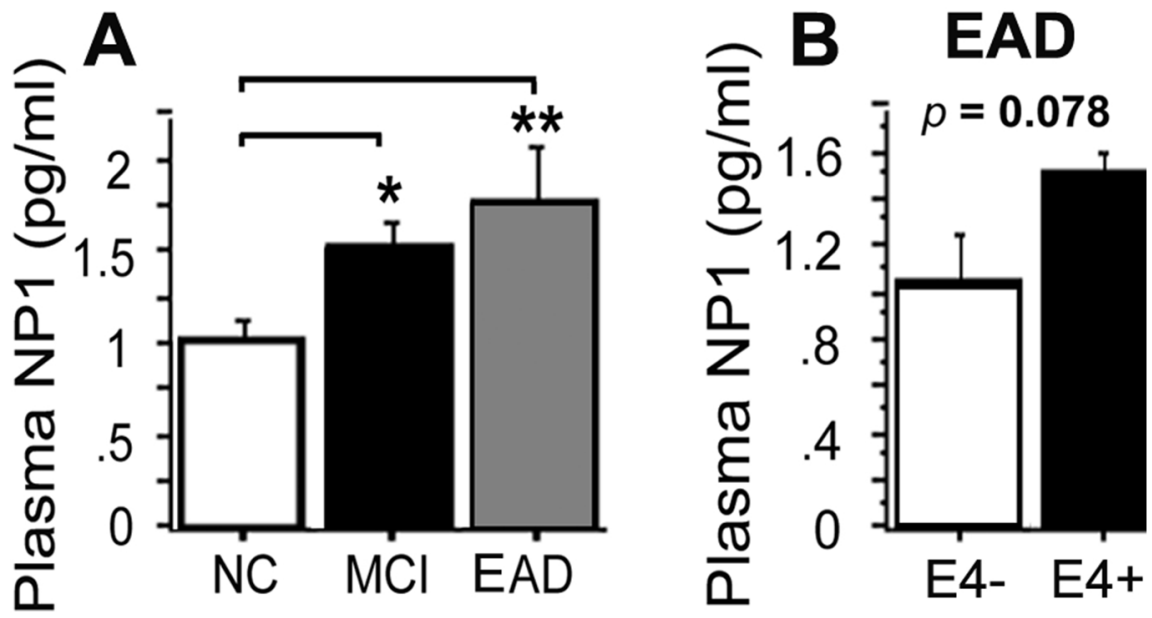

Figure 6 
kDa Pla sup pla sup Exo Exo
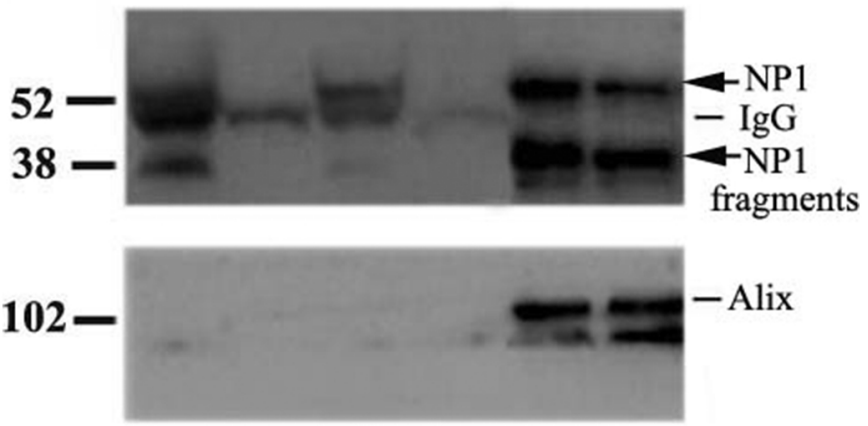

Figure 7 